\title{
AVALIAÇÃO DE POPULAÇÕES DE Butia capitata DE SANTA VITÓRIA DO PALMAR ${ }^{1}$
}

\author{
ELISANE SCHWARTZ2 ${ }^{2}$, JOSÉ CARLOS FACHINELLO ${ }^{3}$, \\ ROSA LÍA BARBIERI ${ }^{4}$, JOÃO BAPTISTA DA SILVA
}

RESUMO - O gênero Butia pertence à família Arecaceae e possui cinco espécies com ocorrência no Rio Grande do Sul. A espécie Butia capitata está recebendo atenção especial, não só pelo seu uso no consumo in natura como também em formas processadas. No entanto, mesmo sendo uma espécie que tem sua utilização registrada desde os tempos pré-históricos, vem sendo explorada apenas de modo extrativista, como a maioria das espécies de frutíferas nativas. Além disso, a espécie está seriamente comprometida em médio prazo pela ausência de regeneração natural e com risco muito alto de extinção num futuro próximo. Nesse sentido, o objetivo deste trabalho foi comparar os frutos, a partir de parâmetros químicos e físicos, e também observar os dados produtivos das plantas de três populações de butiazeiros do município de Santa Vitória do Palmar-RS. Os dados foram obtidos em experimentos conduzidos na safra de 2005/2006 e na safra de 2006/2007, em três propriedades localizadas em Santa Vitória do Palmar. Os resultados permitiram verificar que as propriedades e ou variações genéticas entre as populações de Butia capitata avaliadas propiciaram variabilidade para duração do ciclo, coloração da epiderme dos frutos, volume de suco produzido, relação entre sólidos solúveis totais e acidez titulável, características biométricas de fruto e produtividade anual. Uma das populações, denominada Celina, apresentou maior produtividade e rendimento industrial. As populações Celina e São José apresentaram as melhores características biométricas de fruto. A população Aguiar apresentou a melhor relação entre sólidos solúveis totais e acidez titulável.

Termos para indexação: Butiazeiro, Produção, Qualidade dos frutos.

\section{PERFORMANCE OF Butia capitata POPULATION IN SANTA VITORIA DO PALMAR}

\begin{abstract}
The genus Butia belongs to the Arecaceae family and shows five species occurring in the state of Rio Grande de Sul. The specie Butia capitata requires special attention, not just for its use as fresh consumption but also as processed product. However, even having its use recorded since the pre-historic period this specie has been explored only in an extrativist way as most species of native fruits. Moreover, the specie is seriously committed in the short term by the absence of natural regeneration and a very high risk of extinction in the future. Therefore, the objective of this work was to compare the fruits, from chemical and physical parameters, and as well as to observe the productive data of the trees of three different populations of pindo palm tree in Santa Vitoria do Palmar. The data were obtained in experiments carried out in the 2005/2006 and 2006/2007 seasons at three sites located in Santa Vitoria do Palmar. The results allowed verifying that the populations of Butia capitata assessed in Santa Vitoria do Palmar showed variability for length of cycle, fruit epidermis color, juice volume, relationship between total soluble solids and total titratable acidity, biometric characteristics of fruit and yield. The population denominated Celina showed the highest yield and industrial income. Celina and São José showed the best biometric characteristics of fruit. The population Aguiar had the better relationship between total soluble solids and total titratable acidity. Index terms: Pindo palm tree, yield, fruit quality.
\end{abstract}

\footnotetext{
1(Trabalho 153-09). Recebido em: 18-06-2009. Aceito para publicação em: 20-11-2009. Apoio financeiro: FAPERGS, CAPES. ${ }^{2}$ Eng. Agr ${ }^{a}$, Dr., Prefeitura Municipal de Pelotas, Rua Professor Araújo, 1653, 96020-360, Pelotas-RS-Brasil. E-mail: elisane.schwartz@gmail.com

${ }^{3} \mathrm{Eng}^{\circ}$. Agr ${ }^{\circ}$, Dr., Prof. Titular Depto. Fitotecnia, FAEM-UFPel, C.P. 354, 96010-900, Pelotas-RS-Brasil. E-mail: jfachi@ufpel.edu.br ${ }^{4}$ Bióloga, Dr. , Pesquisadora da Embrapa Clima Temperado, C. P. 403, 96001-970, Pelotas-RS-Brasil. E-mail: lia.barbieri@gmail.com ${ }^{5} \mathrm{Eng}^{\circ}$. Agr ${ }^{\circ}$, Dr., Prof. Titular (aposentado) do Instituto de Física e Matemática da UFPel., Pelotas-RS-Brasil. E-mail: jbs39@terra.com.br
} 


\section{INTRODUÇÃO}

As espécies frutíferas possuem elevado valor econômico, tanto para o comércio de frutas frescas como na produção de matérias-primas para a agroindústria. Além disso, são importantes fontes de alimento e de sustento para as populações de baixa renda em várias partes do País (JESUS, 2009).

Estima-se que a fruticultura comercial envolva apenas vinte espécies, sendo que mais de 3.000 espécies não possuem utilização comercial (LORENZI et al., 2006). Estas espécies são praticamente desconhecidas do grande público e poderiam ser utilizadas não somente in natura, mas também no preparo de sorvetes, sucos, pastas, compotas, geleias, doces cristalizados e licores.

Observa-se que há uma demanda cada vez maior no mercado internacional por frutas com novos aromas, sabores e texturas. Neste contexto, o Brasil, em função da enorme biodiversidade e condições edafoclimáticas, é um país com imenso potencial para fornecer esses recursos naturais vegetais.

Entre as frutíferas nativas, uma família que merece destaque é a Arecaceae, com representantes como o açaí (Euterpe oleraceae), o buriti (Mauritia flexuosa), a guariroba (Syagrus oleracea), o murmuru (Astrocaryum ulei), a pupunheira (Bactris gasipaes), a bacabinha (Oenocarpus minor), o tucumã (Astrocaryum tuсuтa) (LORENZI et al., 2004).

Os representantes desta família mais conhecidos no Sul do Brasil são os jerivás (Syagrus romanzoffiana), butiás (Butia spp.) e juçaras (Euterpe edulis). O butiazeiro produz frutos comestíveis com potencial de exploração da polpa, que pode ser consumida ao natural ou na forma de sorvete, suco, licor e doce. As folhas foram muito utilizadas para cobrir ranchos, fabricar cestas, chapéus e outras obras trançadas, ou para obter crina vegetal, de largo emprego em colchões e obras de estofaria (REITZ et al., 1988).

O uso do butiazeiro no Rio Grande do Sul tem sido reportado desde a pré-história (KERN, 1991). Schmitz et al. (1991) citam o palmar de butiazeiros de Santa Vitória do Palmar como uma importante fonte de coleta de frutos para a alimentação de comunidades indígenas. Atualmente, o butiá é utilizado para a fabricação de licores, sucos, geleias, sorvetes e ainda como planta ornamental. São relatados vários tipos de fruto, com variações no tamanho, na coloração e no sabor (BÜTTOW et al., 2006).

Este recurso genético está seriamente comprometido em médio prazo pela ausência de regeneração natural, e consta no Decreto Estadual 42.009/2002, como uma espécie com risco muito alto de extinção num futuro próximo (Rio Grande do
Sul, 2008). Assim, trabalhos que visem a estudar a variabilidade genética para exploração futura deverão ser iniciados o mais breve possível. O incentivo de seu uso para fins alimentares também pode ser uma excelente estratégia de conservação.

A exploração comercial dos frutos de butiá, até o momento, apresenta pequena expressividade no mercado de frutas, pois os frutos comercializados são obtidos pelo extrativismo. Na literatura consultada, existem poucos trabalhos relacionados a caracteres de interesse agronômico em butiazeiros. Para melhor aproveitamento desta espécie, são necessários conhecimentos mais aprofundados quanto à capacidade produtiva, aspectos qualitativos do fruto e da planta, rendimento e ciclo, entre outras características. Portanto, o objetivo deste trabalho foi caracterizar os frutos a partir de parâmetros químicos e físicos, e também observar os dados produtivos das plantas de três populações de butiazeiros de Santa Vitória do Palmar.

\section{MATERIAL E MÉTODOS}

O trabalho foi realizado em três propriedades particulares, localizadas no município de Santa Vitória do Palmar (RS). Em cada propriedade, foram selecionadas seis plantas adultas homogêneas, ou seja, com o mesmo porte e com idade aproximada de 30 anos (idade estimada pelos proprietários das áreas). Cada local foi considerado uma população, sendo que duas receberam o nome do proprietário (Celina e Aguiar), e outra, o nome da fazenda (São José).

As plantas foram observadas desde o florescimento até a colheita, durante duas safras subsequentes, 2005/2006 e 2006/2007, e não receberam nenhuma forma de manejo cultural ou tratamento com agroquímicos.

As avaliações relativas à planta foram realizadas com base nos seguintes parâmetros: ciclo, número de cachos por planta, comprimento do cacho, número de ráquilas por cacho, número de frutos por cacho e peso do cacho. Para a duração do ciclo, foi considerado o número de dias compreendido entre a plena floração e a colheita, sendo convencionado como plena floração o rompimento da espata e a exposição da inflorescência. Para o comprimento do cacho, tomou-se como padrão a inserção da primeira ráquila na parte basal do cacho, até o ápice do mesmo.

Para avaliar os atributos do fruto, foram retirados aleatoriamente 50 frutos de cada cacho, sendo então mensurado diâmetro do fruto, diâmetro do endocarpo, coloração da epiderme, firmeza, peso do fruto e peso do endocarpo, sendo que os frutos foram considerados maduros quando mudavam de 
coloração, do verde para o amarelo, vermelho, ou laranja, e começavam a se desprender das ráquilas.

Da polpa desses frutos, foi extraído o suco, cujo rendimento foi determinado através do volume de suco de 50 frutos, medido em proveta $(\mathrm{mL})$. Logo após, foram realizadas análises físicas e químicas, de acidez titulável (AT), sólidos solúveis totais (SST), $\mathrm{pH}$ e relação SST/AT, repetidas três vezes para a determinação do valor médio .

A coloração da epiderme dos butiás foi medida com colorímetro eletrônico, marca Minolta 300, usando iluminante D65, com abertura de $8 \mathrm{~mm}$ de diâmetro, calibrado segundo orientação do fabricante. Este aparelho efetua a leitura da cor em escala tridimensional $\mathrm{L}^{*} \mathrm{a}^{*} \mathrm{~b} *$ ou CIELAB, onde os valores de $\mathrm{L}^{*}$ correspondem à luminosidade ou claridade $\mathrm{e}$ variam de 100 (branco) a zero (preto). As coordenadas $a^{*}$ e b* indicam a direção da cor: - $\mathrm{a}^{*}$ corresponde à direção do verde $e+a^{*}$, à direção do vermelho; $-b^{*}$ indica a direção do azul e $+b^{*}$ a direção do amarelo. A partir destes valores, calcularam-se os valores da tonalidade da cor (ângulo $h^{\circ}$ ), expressos em graus pela fórmula $\mathrm{h}^{0}=\tan ^{-1} \mathrm{~b}^{*} / \mathrm{a}^{*}$. Pelo diagrama de cromaticidade $\mathrm{a}^{*}, \mathrm{~b}^{*}$, pode-se verificar a tonalidade da cor dos frutos.

Para as análises físicas e químicas, o suco dos frutos foi extraído utilizando centrífuga. O mesmo foi utilizado para a determinação do teor de sólidos solúveis totais (SST), determinado por leitura direta em refratômetro digital, expressando os resultados em ${ }^{\circ}$ Brix. A acidez titulável (AT) foi medida tomando-se uma alíquota de $10 \mathrm{~mL}$ de suco, diluídos em $90 \mathrm{~mL}$ de água destilada. A amostra foi titulada com $\mathrm{NaOH}$ a $0,1 \mathrm{~N}$ até $\mathrm{pH} 8,2$, em porcentagem de ácido cítrico (Instituto Adolfo Lutz ,1985). Por esses resultados, foi calculada a relação de SST/AT, pelo quociente entre SST e AT.

O experimento fatorial $2 \times 3$ foi conduzido no delineamento experimental inteiramente casualizado, com seis repetições. Os tratamentos avaliados foram três populações (Celina, Aguiar e São José) de butiazeiros em dois anos de observação. Para as variáveis ciclo, número de cachos por planta, número de ráquilas e número de frutos por cacho, foi realizada a transformação raiz $(x+1)$. Os dados foram submetidos à análise da variação, pelo teste $\mathrm{F}$, e as médias foram comparadas pelo teste de Duncan, para $p \leq 0,05$, com emprego do Programa de Estatística SANEST (ZONTA;MACHADO, 1995).

\section{RESULTADOS E DISCUSSÃO}

A safra de butiás de 2005/2006 foi significativamente superior à safra de 2006/2007 para as populações estudadas em relação ao comprimento do ciclo e ao número de cachos por planta, com exceção da população São José, que não apresentou diferença significativa entre uma safra e outra para a variável ciclo (Tabela 1).

A população Celina e a população Aguiar apresentaram um ciclo mais curto na safra de 2006/2007. O número de cachos produzidos na safra de 2005/2006 foi significativamente superior para todas as populações quando comparado com a safra de 2006/2007.

Considerando a safra de butiás de 2005/2006, a população São José mostrou-se mais precoce que a população Celina sem, no entanto, diferir da população Aguiar. A população Celina apresentou a maior média de cachos produzidos por planta, diferindo significativamente das outras duas. $\mathrm{Na}$ safra de 2006/2007, não houve diferença entre as populações para estas variáveis.

Rosa et al. (1998), estudando a mesma espécie na zona da restinga de Santa Catarina, também observaram diferenças entre duas safras quanto ao número de cachos produzidos. As médias por safra foram de 2,24 e 3,08 cachos por planta, em duas safras subsequentes, enquanto as obtidas neste trabalho foram de 5,67 e 2,85 cachos por planta, respectivamente, nas safras de 2005/2006 e 2006/2007, mostrando uma diferença maior entre as safras. A duração do ciclo do desenvolvimento dos frutos, da floração até a maturação, ocorreu em torno de 60,9 dias, no trabalho citado acima, enquanto neste trabalho foi observado, na primeira safra, um ciclo de 89,4 dias e, na segunda, 80,93 dias, caracterizando um ciclo mais longo para os indivíduos de Santa Vitória do Palmar. Isto pode ser explicado pelo fato de as temperaturas médias serem inferiores àquelas de Santa Catarina.

A diferença de produção da planta (número de cachos) de um ano para o outro pode estar associada à alternância de produção ou até mesmo a fatores climáticos. Já o encurtamento do ciclo observado na segunda safra pode estar diretamente ligado à temperatura média e insolação mais alta, bem como ao maior índice pluviométrico, que pode ter acelerado $\mathrm{o}$ amadurecimento e, consequentemente, o encurtamento do ciclo (Tabelas 2 e 3 ).

O comprimento de cacho de uma safra para outra não foi alterado de forma significativa e entre as populações estudadas (Tabela 4). O comprimento 
do cacho variou de 99,0 até $113,4 \mathrm{~cm}$. Esses valores estão próximos dos obtidos por Morel et al. (2005), que obtiveram uma média de $108,7 \mathrm{~cm}$ para a mesma espécie.

Para o número de ráquilas, não houve diferenças entre as safras, mas houve diferenças significativas entre as populações, considerando os dois anos de produção. As populações São José e Aguiar apresentaram as maiores médias de número de ráquilas, diferindo significativamente da população Celina.

O número médio de ráquilas, nos dois anos de estudo, ficou bem acima do relatado por Rosa et al. (1998), Fonseca et al. (2007) e Morel et al. (2005), que obtiveram a média de 64,13; 89,65 e 97 ráquilas, respectivamente.

O peso do cacho e o número de frutos por cacho não diferiram significativamente nas duas safras de avaliação, nas diferentes populações (Tabela 5).

Considerando a média geral de cachos produzidos por planta e o peso médio dos mesmos, pode-se inferir que, para as condições de Santa Vitória do Palmar, a produção é de $56,0 \mathrm{~kg}$ por planta. Rivas e Barilani (2004) verificaram a média de 16,6 $\mathrm{kg}$ de frutos para butiazeiros no Departamento de Rocha, Uruguai. Esta diferença pode ser atribuída principalmente à idade dos indivíduos estudados, sendo os indivíduos do Uruguai mais velhos que os de Santa Vitória do Palmar, mas também pode estar associada a fatores edafoclimáticos.

O butiazeiro possui um rendimento bem maior do que outras espécies de palmeiras, como, por exemplo, o açaizeiro, uma espécie conhecida nacionalmente, que produz em média cachos com 4 kg (ROGEZ, 2000) e também maior do que os cachos de murmuru, uma palmeira da região amazônica, que possui cachos com peso médio de 8,2 $\mathrm{kg}$ (NASCIMENTO et al., 2007).

A média geral para o número de frutos por cacho foi de 1.136,95. Rivas e Barilani (2004), estudando a mesma espécie, no Uruguai, observaram a média geral de 1.208,8 frutos/infrutescência. Nunes (2007) verificou que o número médio de frutos variou de 22 a 1.036,33, para butiazeiros da coleção de germoplasma da UFPel.

Quando se compara com outras espécies de palmeiras, o butiazeiro possui maior número de frutos por cacho, como, por exemplo, o murmuru, que produz em média 552 frutos por cacho (NASCIMENTO et al., 2007) ou o jauari (Astrocaryum jauari), que produz a média de 106 frutos por cacho (PIEDADE et al., 2003).

Para o diâmetro médio do fruto e do endocarpo, houve diferença significativa entre as popula- ções, levando em conta as duas safras (Tabela 6). As populações São José e Celina apresentaram os maiores diâmetros de fruto, diferindo significativamente da população Aguiar. Para diâmetro do endocarpo, o valor mais alto foi obtido pela população São José, que diferiu significativamente da população Aguiar.

As médias de diâmetro do fruto estão acima das encontradas por Rivas e Barilani (2004), que obtiveram a média de $22,4 \mathrm{~mm}$, enquanto a média geral das populações neste estudo, para as duas safras, ficou acima de $27 \mathrm{~mm}$. Nunes (2007) encontrou a média de 25,41 mm para 11 genótipos de butiazeiro estudados.

Houve diferenças significativas entre populações para peso médio do fruto e peso médio do endocarpo (Tabela 7). As populações Celina e São José foram significativamente superiores à população Aguiar para peso médio do fruto, comportamento que já havia sido observado para diâmetro do fruto.

Rivas e Barilani (2004) obtiveram a média de 6,9 gramas para peso do fruto, valor abaixo do verificado nas duas safras, neste experimento $(11,61$ e 12,27), respectivamente, na safra de 2005/2006 e 2006/2007. Enquanto Rossato (2007) obteve a média de $16,95 \mathrm{~g}$ para a mesma espécie, média superior à encontrada neste trabalho. Estas diferenças podem ser atribuídas às condições edafoclimáticas ou até mesmo a diferenças genotípicas.

O peso médio do endocarpo acompanhou os dados de diâmetro médio do endocarpo, ou seja, a população São José apresentou o maior peso, diferindo significativamente da população Aguiar. A diferença entre populações, para esta variável, foi encontrada também por Rivas e Barilani (2004), que observaram que a população de Castillos possuía média maior que a população de San Luis. No entanto, a média geral encontrada por estes autores, 1,9 grama, foi inferior à encontrada neste trabalho, no qual se obteve como média geral 2,35 gramas, semelhante aos dados relatados por Molina (2001).

A firmeza dos frutos diferiu significativamente entre os dois anos analisados, sendo que os frutos da safra de 2006/2007 apresentaram maior resistência de polpa que os colhidos em 2005/2006 (Tabela 8). Isto pode ser atribuído ao comprimento de ciclo menor na segunda safra, o que pode ter influenciado na qualidade dos frutos. Nunes (2007), estudando vários genótipos de butiazeiro, verificou a média de 6,98 libras, valor inferior ao encontrado neste trabalho. Isso pode ser atribuído ao ponto de colheita ou à variabilidade entre os indivíduos. A firmeza da polpa é representada por substâncias pécticas que compõem as paredes celulares. À medida que a fruta amadurece, essas substâncias tornam-se solúveis e ocorre o amaciamento da polpa (KLUGE et al., 1997). A firmeza 
está diretamente relacionada à maturação da fruta, mas quanto mais madura, menos firme e menor será sua vida de prateleira.

Quanto ao volume de suco, houve diferença significativa na população Celina de uma safra para outra, sendo que a safra de 2006/2007 foi melhor, ou seja, produziu mais suco. Também, considerando a última safra houve diferença significativa entre as populações, sendo que a população Celina se destacou das demais, produzindo mais suco. Esta característica é relevante quando se pensa na industrialização desta fruta, uma vez que existem genótipos que conferem rendimento maior.

Para $\mathrm{pH}$ e SST, nenhum dos fatores estudados foi significativo (Tabela 9). O valor médio de $\mathrm{pH}$ foi de 3,05 , e de SST, 11,71. Os valores de $\mathrm{pH}$ obtidos neste estudo estão próximos àqueles obtidos por Dal Magro et al. (2006) para outra espécie de butiá, Butia eriospatha, e também semelhantes aos de Schlindwein et al. (2006) para butiazeiros de Arambaré (RS). Os valores de sólidos solúveis totais dos butiás coletados em Santa Vitória do Palmar (11,71 Brix) são superiores aos encontrados para Butia eriospatha, com 6,4 e 7,7 $7^{\circ}$ Brix para as amostras do Paraná e Santa Catarina, respectivamente. Nunes (2007) verificou valores de SST entre 12,0 e $18^{\circ}$ Brix para frutas da coleção de germoplasma em Pelotas, e Schlindwein et al. (2006) verificaram valores que variaram de 10,28 a $14,25^{\circ}$ Brix, para butiazeiros localizados no município de Arambaré. Estas diferenças podem estar associadas a condições edafoclimáticas e ao grau de maturação das frutas.

A acidez titulável das frutas foi diferente de uma safra para outra para a população Celina, sendo que, na safra de 2006/2007, apresentou maior percentual de acidez (Tabela 10). O teor de acidez é importante, pois contribui para a manutenção das características do fruto durante o armazenamento, uma vez que inibe o crescimento microbiano, principalmente de mofos e leveduras (BORGES et al., 2006); além disso, proporciona maior rendimento nas indústrias de suco, segundo Andrade et al. (1993).

A relação SST/AT nas frutas foi diferente de um ano para outro para a população Aguiar, sendo que esta relação foi mais alta na safra de 2005/2006. Na safra de 2005/2006, houve diferença significativa entre as populações, sendo que a população Aguiar apresentou o valor mais alto, diferindo das populações Celina e São José. Isto pode estar relacionado ao fato de que, na população Aguiar, a maturação dos frutos ocorreu mais tarde do que nas outras populações.

Segundo Chitarra e Chitarra (1990), a relação SST/AT é uma das melhores formas de avaliação do sabor, sendo mais representativa que a medição isolada de açúcares ou da acidez. Entretanto, há necessidade de conhecer os teores de SST e AT para se ter uma ideia real do sabor.

Com relação à análise colorimétrica, todas as médias de coloração de polpa localizaram-se dentro do primeiro quadrante, apresentando valores positivos de $a^{*}$ e $b^{*}$, ou seja, cores vermelha e amarela. Houve diferenças significativas entre as populações (Tabela 11), sendo que, na safra de 2005/2006, a população Celina apresentou o mais alto valor de vermelho, diferindo significativamente da população Aguiar. Houve diferenças significativas para o ângulo Hue (Tabela 12), e intensidade da cor entre as populações. A população Aguiar diferiu significativamente da população Celina, sendo que esta última apresentou menor ângulo, determinando maior intensidade de vermelho, não diferindo, no entanto, da população São José.

Para os valores de $\mathrm{L}^{*}$, que correspondem à luminosidade, e para o valor de $b^{*}$, que exprime coloração amarela, não houve diferenças entre os fatores estudados (Tabelas 9 e 10). 
TABELA 1 - Valores médios de comprimento do ciclo e número de cachos por planta, obtidos na observação de três populações de butiazeiros, durante duas safras, em Santa Vitória do Palmar (RS), 2005/2006 e 2006/2007.

\begin{tabular}{ccccccc}
\hline \multirow{2}{*}{ Populações } & \multicolumn{3}{c}{ Ciclo (dias) } & \multicolumn{3}{c}{$\mathrm{N}^{\circ}$ de cachos/planta } \\
\cline { 2 - 7 } & Safra 05/06 & Safra 06/07 & Média & Safra 05/06 & Safra 06/07 & Média \\
\hline Aguiar & $90,90 \mathrm{Aab}$ & $82,55 \mathrm{Ba}$ & $\mathbf{8 6 , 7 2 a}$ & $5,30 \mathrm{Ab}$ & $2,76 \mathrm{Ba}$ & $\mathbf{4 , 0 3 b}$ \\
Celina & $93,45 \mathrm{Aa}$ & $82,01 \mathrm{Ba}$ & $\mathbf{8 7 , 7 3 a}$ & $7,28 \mathrm{Aa}$ & $3,51 \mathrm{Ba}$ & $\mathbf{5 , 3 9 a}$ \\
São José & $83,85 \mathrm{Ab}$ & $78,23 \mathrm{Aa}$ & $\mathbf{8 1 , 0 4 b}$ & $4,43 \mathrm{Ab}$ & $2,28 \mathrm{Ba}$ & $\mathbf{3 , 3 5 b}$ \\
Média & $\mathbf{8 9 , 4 0 A}$ & $\mathbf{8 0 , 9 3 B}$ & & $\mathbf{5 , 6 7 A}$ & $\mathbf{2 , 8 5 B}$ & \\
CV(\%) & 3,66 & & & 12,25 & & \\
\hline
\end{tabular}

Médias seguidas pela mesma letra maiúscula na linha e minúscula na coluna não diferem, pelo teste de Duncan, ao nível de 5\% de significância de probabilidade de erro.

TABELA 2 - Dados climáticos safra de 2005/2006.

\begin{tabular}{lccccccccc}
\hline & Out. & Nov. & Dez. & Jan. & Fev. & Mar. & Abr. & Maio & \multirow{2}{*}{ Médias } \\
& 2005 & 2005 & 2005 & 2006 & 2006 & 2006 & 2006 & 2006 & \\
\hline Temperatura Máxima $\left({ }^{\circ} \mathrm{C}\right)$ & 20,4 & 25,8 & 25,0 & 27,5 & 27,7 & 25,8 & 23,1 & 18,9 & 24,27 \\
Temperatura Mínima $\left({ }^{\circ} \mathrm{C}\right)$ & 10,5 & 13,9 & 14,3 & 17,9 & 16,9 & 16,5 & 13,7 & 8,9 & 14,07 \\
Temperatura Média $\left({ }^{\circ} \mathrm{C}\right)$ & 15,5 & 19,9 & 19,6 & 22,7 & 22,3 & 21,1 & 18,4 & 13,9 & 19,17 \\
Precipitações & 78,5 & 21,0 & 27,7 & 72,1 & 119,6 & 182,7 & 53,2 & 21,0 & 71,97 \\
Insolação & 224,0 & 289,1 & 266,0 & 226,5 & 178,4 & 224,4 & 193,3 & 181,7 & 222,92 \\
\hline
\end{tabular}

Fonte: IRGA, Santa Vitória do Palmar.

TABELA 3 - Dados climáticos safra 2006/2007.

\begin{tabular}{lccccccccc}
\hline & Out. & Nov. & Dez. & Jan. & Fev. & Mar. & Abr. & Maio & \multirow{2}{*}{ Médias } \\
& 2006 & 2006 & 2006 & 2007 & 2007 & 2007 & 2007 & 2007 & \\
\hline Temperatura Máxima $\left({ }^{\circ} \mathrm{C}\right)$ & 22,4 & 23,4 & 27,7 & 28,8 & 28,9 & 26,3 & 24,0 & 16,3 & 24,72 \\
Temperatura Mínima $\left({ }^{\circ} \mathrm{C}\right)$ & 12,6 & 13,4 & 17,7 & 18,1 & 18,6 & 18,1 & 15,0 & 8,6 & 15,26 \\
Temperatura Média $\left({ }^{\circ} \mathrm{C}\right)$ & 17,5 & 18,4 & 22,7 & 23,5 & 23,7 & 22,2 & 19,5 & 12,5 & 20,00 \\
Precipitações & 97,5 & 40,8 & 59,6 & 15,8 & 293,4 & 297,0 & 71,10 & 103,6 & 122,35 \\
Insolação & 206,8 & 246,5 & 248,9 & 272,5 & 276,0 & 164,1 & 185,1 & 191,9 & 223,97 \\
\hline
\end{tabular}

Fonte: IRGA, Santa Vitória do Palmar.

TABELA 4 - Valores médios de comprimento do cacho e número de ráquilas por cacho, obtidos na observação de três populações de butiazeiros, durante duas safras, em Santa Vitória do Palmar (RS), 2005/2006 e 2006/2007.

\begin{tabular}{lllllll}
\hline & \multicolumn{2}{c}{ Comprimento de cacho $(\mathrm{cm})$} & \multicolumn{3}{c}{ Número de ráquilas } \\
\cline { 2 - 7 } Populações & Safra 05/06 & Safra 06/07 & Média & Safra 05/06 & Safra 06/07 & Média \\
& & & & & & \\
\hline Aguiar & $99,00 \mathrm{Aa}$ & $103,27 \mathrm{Aa}$ & $\mathbf{1 0 1 , 1 3 b}$ & $139,74 \mathrm{Aa}$ & $145,12 \mathrm{Aa}$ & $\mathbf{1 4 2 , 4 3 a}$ \\
Celina & $108,94 \mathrm{Aa}$ & $107,47 \mathrm{Aa}$ & $\mathbf{1 0 8 , 2 0 a b}$ & $129,65 \mathrm{Aa}$ & $130,76 \mathrm{Aa}$ & $\mathbf{1 3 0 , 2 0 b}$ \\
São José & $110,83 \mathrm{Aa}$ & $113,41 \mathrm{Aa}$ & $\mathbf{1 1 2 , 1 2 a}$ & $144,93 \mathrm{Aa}$ & $143,29 \mathrm{Aa}$ & $\mathbf{1 4 4 , 1 1 a}$ \\
Média & $\mathbf{1 0 6 , 2 6 A}$ & $\mathbf{1 0 8 , 0 5 A}$ & & $\mathbf{1 3 8 , 1 1 A}$ & $\mathbf{1 3 9 , 7 2 A}$ & \\
CV $(\%)$ & 10,36 & & & 4,76 & & \\
\hline
\end{tabular}

Médias seguidas pela mesma letra maiúscula na linha e minúscula na coluna não diferem, pelo teste de Duncan, ao nível de $5 \%$ de significância de probabilidade de erro. 
TABELA 5 - Valores médios de peso do cacho e número de frutos por cacho, obtidos na observação de três populações de butiazeiros, durante duas safras, em Santa Vitória do Palmar (RS), 2005/2006 e $2006 / 2007$.

\begin{tabular}{ccccccc}
\hline & \multicolumn{3}{c}{ Peso do cacho $(\mathrm{kg})$} & \multicolumn{3}{c}{ Número de frutos } \\
\cline { 2 - 7 } Populações & Safra 05/06 & Safra 06/07 & Média & Safra05/06 & Safra 06/07 & Média \\
& & & & & & \\
\hline Aguiar & 8,99 & 11,39 & $\mathbf{1 0 , 1 9}$ & 959,63 & 1012,89 & $\mathbf{9 8 6 , 2 6}$ \\
Celina & 15,61 & 14,99 & $\mathbf{1 5 , 3 0}$ & 1409,84 & 1064,32 & $\mathbf{1 2 3 7 , 0 8}$ \\
São José & 13,64 & 14,27 & $\mathbf{1 3 , 9 5}$ & 1155,67 & 1219,36 & $\mathbf{1 1 8 7 , 5 1}$ \\
Média & $\mathbf{1 2 , 7 5}$ & $\mathbf{1 3 , 5 5}$ & & $\mathbf{1 1 7 5 , 0 5}$ & $\mathbf{1 0 9 8 , 8 6}$ & \\
CV (\%) & 44,49 & & & 17,00 & & \\
\hline
\end{tabular}

Médias não diferem pelo teste de Duncan, ao nível de 5\% e significância de probabilidade de erro.

TABELA 6 - Valores médios de diâmetro de frutos e de endocarpos, obtidos na observação de três populações de butiazeiros, durante duas safras, em Santa Vitória do Palmar (RS), 2005/2006 e 2006/2007.

\begin{tabular}{ccccccc}
\hline & \multicolumn{3}{c}{ Diâmetro de frutos $(\mathrm{mm})$} & \multicolumn{3}{c}{ Diâmetro de endocarpos (mm) } \\
\cline { 2 - 7 } Populações & Safra 05/06 & Safra 06/07 & Média & Safra 05/06 & Safra 06/07 & Média \\
& & & & & & \\
\hline Aguiar & $25,44 \mathrm{Aa}$ & $26,52 \mathrm{Aa}$ & $\mathbf{2 5 , 9 8 b}$ & $13,63 \mathrm{Aa}$ & $13,55 \mathrm{Aa}$ & $\mathbf{1 3 , 5 9 b}$ \\
Celina & $27,81 \mathrm{Aa}$ & $28,63 \mathrm{Aa}$ & $\mathbf{2 8 , 2 2 a}$ & $13,84 \mathrm{Aa}$ & $13,94 \mathrm{Aa}$ & $\mathbf{1 3 , 8 9 a b}$ \\
São José & $28,30 \mathrm{Aa}$ & $28,07 \mathrm{Aa}$ & $\mathbf{2 8 , 1 8 a}$ & $14,75 \mathrm{Aa}$ & $15,06 \mathrm{Aa}$ & $\mathbf{1 4 , 9 0 a}$ \\
Média & $\mathbf{2 7 , 1 8 A}$ & $\mathbf{2 7 , 7 4 A}$ & & $\mathbf{1 4 , 0 7 A}$ & $\mathbf{1 4 , 1 8 A}$ & \\
CV $(\%)$ & 8,60 & & & 9,23 & & \\
\hline
\end{tabular}

Médias seguidas pela mesma letra maiúscula na linha e minúscula na coluna não diferem, pelo teste de Duncan, ao nível de 5\% de significância de probabilidade de erro.

TABELA 7 - Valores médios de peso dos frutos e dos endocarpos obtidos na observação de três populações de butiazeiros, durante duas safras, em Santa Vitória do Palmar (RS), 2005/2006 e 2006/2007.

\begin{tabular}{lllllll}
\hline & \multicolumn{3}{c}{ Peso do fruto $(\mathrm{g})$} & \multicolumn{3}{c}{ Peso do endocarpo $(\mathrm{g})$} \\
\cline { 2 - 7 } Populações & Safra 05/06 & Safra 06/07 & Média & Safra 05/06 & Safra 06/07 & Média \\
& & & & & & \\
\hline Aguiar & $10,04 \mathrm{Aa}$ & $10,56 \mathrm{Aa}$ & $\mathbf{1 0 , 3 0 A b}$ & $2,08 \mathrm{Aa}$ & $2,07 \mathrm{Aa}$ & $\mathbf{2 , 0 7 b}$ \\
Celina & $12,30 \mathrm{Aa}$ & $13,88 \mathrm{Aa}$ & $\mathbf{1 3 , 0 9 A a}$ & $2,23 \mathrm{Aa}$ & $2,45 \mathrm{Aa}$ & $\mathbf{2 , 3 4 a b}$ \\
São José & $12,49 \mathrm{Aa}$ & $12,37 \mathrm{Aa}$ & $\mathbf{1 2 , 4 3 A a}$ & $2,50 \mathrm{Aa}$ & $2,80 \mathrm{Aa}$ & $\mathbf{2 , 6 5 a}$ \\
Média & $\mathbf{1 1 , 6 1 A}$ & $\mathbf{1 2 , 2 7 A}$ & & $\mathbf{2 , 2 7 A}$ & $\mathbf{2 , 4 4 A}$ & \\
CV $(\%)$ & 19,94 & & & 21,12 & & \\
\hline
\end{tabular}

Médias seguidas pela mesma letra maiúscula na linha e minúscula na coluna não diferem, pelo teste de Duncan, ao nível de 5\% de significância de probabilidade de erro.

TABELA 8 - Valores médios de firmeza da polpa e volume de suco de frutos de butiazeiros de três populações diferentes, observados durante duas safras, em Santa Vitória do Palmar (RS), 2005/2006 e 2006/2007.

\begin{tabular}{ccccccc}
\hline & \multicolumn{3}{c}{ Firmeza (lb) } & \multicolumn{3}{c}{ Volume de suco $(\mathrm{mL})$} \\
\cline { 2 - 7 } Populações & Safra 05/06 & Safra 06/07 & Média & Safra 05/06 & Safra 06/07 & Média \\
& & & & & & \\
\hline Aguiar & $9,25 \mathrm{Aa}$ & $12,12 \mathrm{Aa}$ & $\mathbf{1 0 , 6 8 a}$ & $144,89 \mathrm{Aa}$ & $171,10 \mathrm{Ab}$ & $\mathbf{1 5 7 , 9 9 b}$ \\
Celina & $8,81 \mathrm{Aa}$ & $10,69 \mathrm{Aa}$ & $\mathbf{9 , 7 5 a}$ & $183,80 \mathrm{Aa}$ & $258,23 \mathrm{Ba}$ & $\mathbf{2 2 1 , 0 1 a}$ \\
São José & $9,37 \mathrm{Aa}$ & $12,21 \mathrm{Aa}$ & $\mathbf{1 0 , 7 9 a}$ & $169,39 \mathrm{Aa}$ & $168,00 \mathrm{Ab}$ & $\mathbf{1 6 8 , 6 9 b}$ \\
Média & $\mathbf{9 , 1 4 B}$ & $\mathbf{1 1 , 6 7 A}$ & & $\mathbf{1 6 6 , 0 3 A}$ & $\mathbf{1 9 9 , 0 0 A}$ & \\
CV $(\%)$ & 31,38 & & & 27,87 & & \\
\hline
\end{tabular}

Médias seguidas pela mesma letra maiúscula na linha e minúscula na coluna não diferem, pelo teste de Duncan, ao nível de $5 \%$ de significância de probabilidade de erro. 
TABELA 9 - Valores médios de pH e sólidos solúveis totais (SST) de frutos de três populações diferentes de butiazeiros, observados durante duas safras, em Santa Vitória do Palmar (RS), 2005/2006 e 2006/2007.

\begin{tabular}{ccccccc}
\hline & \multicolumn{3}{c}{$\mathrm{pH}$} & \multicolumn{3}{c}{ SST $\left({ }^{0} \mathrm{Brix}\right)$} \\
\cline { 2 - 7 } Populações & Safra 05/06 & Safra 06/07 & \multirow{2}{*}{ Média } & Safra 05/06 & Safra 06/07 & \multirow{2}{*}{ Média } \\
\hline Aguiar & $3,09 \mathrm{Aa}$ & $3,08 \mathrm{Aa}$ & $\mathbf{3 , 0 8 a}$ & $12,50 \mathrm{Aa}$ & $11,46 \mathrm{Aa}$ & $\mathbf{1 1 , 9 8 a}$ \\
Celina & $3,04 \mathrm{Aa}$ & $2,98 \mathrm{Aa}$ & $\mathbf{3 , 0 1 a}$ & $11,96 \mathrm{Aa}$ & $11,58 \mathrm{Aa}$ & $\mathbf{1 1 , 7 7 a}$ \\
São José & $3,04 \mathrm{Aa}$ & $3,07 \mathrm{Aa}$ & $\mathbf{3 , 0 5 a}$ & $11,81 \mathrm{Aa}$ & $10,96 \mathrm{Aa}$ & $\mathbf{1 1 , 3 8 a}$ \\
Média & $\mathbf{3 , 0 6 A}$ & $\mathbf{3 , 0 4 A}$ & & $\mathbf{1 2 , 0 9 A}$ & $\mathbf{1 1 , 3 3 A}$ & \\
CV $(\%)$ & 3,29 & & & 11,18 & & \\
\hline
\end{tabular}

Médias seguidas pela mesma letra maiúscula na linha e minúscula na coluna não diferem, pelo teste de Duncan, ao nível de 5\% de significância de probabilidade de erro.

TABELA 10 - Valores médios de acidez titulável (AT) e SST/AT de frutos de três populações diferentes, observados durante duas safras, em Santa Vitória do Palmar (RS), 2005/2006 e 2006/2007.

\begin{tabular}{ccccccc}
\hline & \multicolumn{3}{c}{ ATT (\% de ácido cítrico) } & \multicolumn{3}{c}{ SST/AT } \\
\cline { 2 - 7 } Populações & Safra 05/06 & Safra 06/07 & Média & Safra 05/06 & Safra 06/07 & Média \\
& & & & & & \\
\hline Aguiar & $1,96 \mathrm{Aa}$ & $2,41 \mathrm{Aa}$ & $\mathbf{2 , 1 8 a}$ & $6,81 \mathrm{Aa}$ & $5,19 \mathrm{Ba}$ & $\mathbf{6 , 0 0 a}$ \\
Celina & $2,31 \mathrm{Ba}$ & $2,87 \mathrm{Aa}$ & $\mathbf{2 , 5 9 a}$ & $5,27 \mathrm{Ab}$ & $4,17 \mathrm{Aa}$ & $\mathbf{4 , 7 2 b}$ \\
São José & $2,34 \mathrm{Aa}$ & $2,54 \mathrm{Aa}$ & $\mathbf{2 , 4 4 a}$ & $5,19 \mathrm{Ab}$ & $4,62 \mathrm{Aa}$ & $\mathbf{4 , 9 0 b}$ \\
Média & $\mathbf{2 , 2 0 B}$ & $\mathbf{2 , 6 1 A}$ & & $\mathbf{5 , 7 6 A}$ & $\mathbf{4 , 6 6 B}$ & \\
CV $(\%)$ & 18,05 & & & 23,75 & & \\
\hline
\end{tabular}

Médias seguidas pela mesma letra maiúscula na linha e minúscula na coluna não diferem, pelo teste de Duncan, ao nível de 5\% de significância de probabilidade de erro.

TABELA 11 - Caracterização cromática $\left(\mathrm{a}^{*} \mathrm{~b}^{*}\right)$ da casca de butiazeiros de três populações observadas por duas safras, em Santa Vitória do Palmar (RS), 2005/2006 e 2006/2007.

\begin{tabular}{ccccccc}
\hline & \multicolumn{3}{c}{ Valor a* } & \multicolumn{3}{c}{ Valor b* } \\
\cline { 2 - 7 } Populações & Safra 05/06 & Safra 06/07 & Média & Safra 05/06 & Safra 06/07 & Média \\
& & & & & & \\
\hline Aguiar & $9,21 \mathrm{Ab}$ & $11,21 \mathrm{Aa}$ & $\mathbf{1 0 , 2 1 b}$ & $44,15 \mathrm{Aa}$ & $49,44 \mathrm{Aa}$ & $\mathbf{4 6 , 7 9 a}$ \\
Celina & $14,42 \mathrm{Aa}$ & $16,38 \mathrm{Aa}$ & $\mathbf{1 5 , 4 0 a}$ & $41,30 \mathrm{Aa}$ & $45,38 \mathrm{Aa}$ & $\mathbf{4 3 , 3 4 a}$ \\
São José & $10,89 \mathrm{Aab}$ & $12,42 \mathrm{Aa}$ & $\mathbf{1 1 , 6 5 b}$ & $43,59 \mathrm{Aa}$ & $44,29 \mathrm{Aa}$ & $\mathbf{4 3 , 9 4 a}$ \\
\hline Média & $\mathbf{1 1 , 5 1 A}$ & $\mathbf{1 3 , 3 4 A}$ & & $\mathbf{4 3 , 0 1 a}$ & $\mathbf{4 6 , 3 7 A}$ & \\
CV $(\%)$ & $30,22 \%$ & & & $12,11 \%$ & & \\
\hline
\end{tabular}

Médias seguidas pela mesma letra maiúscula na linha e minúscula na coluna não diferem, pelo teste de Duncan, ao nível de 5\% de significância de probabilidade de erro.

TABELA 12 - Caracterização cromática (ângulo Hue e L*) da casca de butiazeiros de três populações observadas por duas safras em Santa Vitória do Palmar, 2005/2006 e 2006/2007.

\begin{tabular}{ccccccc}
\hline & \multicolumn{3}{c}{ Angulo Hue } & \multicolumn{3}{c}{ Valor L* } \\
\cline { 2 - 7 } Populações & Safra 05/06 Safra 06/07 & Média & Safra 05/06 & Safra 06/07 & \multirow{2}{*}{ Média } \\
\hline Aguiar & $77,87 \mathrm{Aa}$ & $77,38 \mathrm{Aa}$ & $\mathbf{7 7 , 6 2 a}$ & $69,53 \mathrm{Aa}$ & $74,10 \mathrm{Aa}$ & $\mathbf{7 1 , 8 1 a}$ \\
Celina & $70,24 \mathrm{Aa}$ & $70,19 \mathrm{Aa}$ & $\mathbf{7 0 , 2 1 b}$ & $65,10 \mathrm{Aa}$ & $66,46 \mathrm{Aa}$ & $\mathbf{6 5 , 7 8 a}$ \\
São José & $75,35 \mathrm{Aa}$ & $73,39 \mathrm{Aa}$ & $\mathbf{7 4 , 3 7 a b}$ & $70,19 \mathrm{Aa}$ & $68,09 \mathrm{Aa}$ & $\mathbf{6 9 , 1 4 a}$ \\
\hline Média & $\mathbf{7 4 , 4 9 A}$ & $\mathbf{7 3 , 6 5 A}$ & & $\mathbf{6 8 , 2 7 A}$ & $\mathbf{6 9 , 5 5 A}$ & \\
CV $(\%)$ & $7,98 \%$ & & & $8,40 \%$ & & \\
\hline
\end{tabular}

Médias seguidas pela mesma letra maiúscula na linha e minúscula na coluna não diferem, pelo teste de Duncan, ao nível de 5\% de significância de probabilidade de erro. 


\section{CONCLUSÕES}

1-As propriedades e ou variações genéticas entre as populações de Butia capitata, avaliadas em Santa Vitória do Palmar, propiciam diferenças entre si quanto ao comprimento do ciclo, coloração da epiderme dos frutos, volume de suco produzido, relação entre sólidos solúveis totais e acidez total titulável, características biométricas de fruto e produtividade anual.

2-A população Celina destaca-se em termos de produtividade e rendimento industrial.

3-As populações Celina e São José apresentam melhores características biométricas de fruto, tais como diâmetro e peso médio.

4-A população Aguiar apresenta a melhor relação entre sólidos solúveis totais e acidez total titulável.

\section{REFERÊNCIAS}

ANDRADE, J. de S.; ARAGÃO, C. G.; FERREIRA, S. A. do N. Caracterização física e química dos frutos de Araçá- Pera (Psidium acutangulum D. C.). Acta Amazônica, Manaus, v.23, n.2-3, p.213-217, 1993.

BORGES, G. da S.; SGANZERLA, M.; ZAMBIAZI, R. C. Caracterização química de frutos de butiá. In: CONGRESSO DE CIÊNCIAS FARMACÊUTICAS DE CASCAVEL E SIMPÓSIO EM CIÊNCIA E TECNOLOGIA DE ALIMENTOS DO MERCOSUL, 2., 2006, Cascavel. Anais... Cascavel: Unioeste, 2006.

BÜTTOW, M. V.; NEITZKE, R. S.; FISCHER, S. Z.;HEIDEN G.; BARBIERI, R.L. Etnobotânica de butiá em Pelotas, Turuçu e Rio Grande. In: ENCONTRO DE INICIAÇÃO CIENTÍFICA E PÓS-GRADUAÇÃO DA EMBRAPA CLIMATEMPERADO: IDEIAS, TECNOLOGIA E INOVAÇÃO, 1., 2006, Pelotas. Anais... Pelotas: Embrapa Clima Temperado, 2006. p.95-98.

CHITARRA, M. I. F.; CHITARRA, A. B. Pós-colheita de frutas e hortaliças: fisiologia e manuseio. Lavras: ESAL/FAEPE, 1990. 320p.

DAL MAGRO, N. G.; COELHO, S. R. M.; HAIDA, K. S.; BERTÉ, S. D.; MORAES, S.S. de. Comparação físico-química de frutos congelados de Butia eriosphata (Mart.) Becc. do Paraná e Santa Catarina - Brasil. Revista Varia Scientia, Cascavel, v.6, n.11, p.33-42, 2006.
FONSECA, R. S.; RIBEIRO, L. M.; SIMÕES, M. O. M.; MENINO, G. C.de O.; JESUS, F. M. de; REIS, S.B. Morfometria da flor e inflorescência de Butia capitata (Mart) Becc. (Arecaceae) em diferentes fases de desenvolvimento, no cerrado de Montes Claros - MG. Revista Brasileira de Biociências, Porto Alegre, v.5, p.657-659, 2007. Suplemento.

INSTITUTO ADOLFO LUTZ. Normas analíticas: métodos químicos e físicos para análises de alimentos. 3.ed. São Paulo: Instituto Adolfo Lutz, 1985. v.1, 533p.

JESUS, N. de. Mercado de venda por consignação de frutíferas. Toda Fruta, Jaboticabal. Disponível em: $<$ http://www.todafruta.com.br/todafruta/mostra conteudo.asp? conteudo=9092 $>$. Acesso em: 08 set.2009.

KERN, A. Arqueologia pré-histórica do Rio Grande do Sul. Porto Alegre: Mercado Aberto, 1991. 356p. (Série Documenta).

KLUGE, R. A.; NACHTIGAL, J. C.; FACHINELLO, J. C.; BILHALVA, A. B. Fisiologia e manejo pós-colheita de frutas de clima temperado. Pelotas: Editora UFPel, 1997. 163p.

LORENZI, H.; BACHER, L.; LACERDA, M.; SARTORI, S. Frutas brasileiras e exóticas cultivadas (de consumo in natura). São Paulo: Instituto Plantarum de Estudos da Flora, 2006. 672p.

LORENZI, H.; SOUZA, H. M. de; COSTA, J. T. de M.; CERQUEIRA, L. S. C. de; FERREIRA, E. Palmeiras brasileiras e exóticas cultivadas. Nova Odessa: Instituto Plantarum, 2004. 416 p.

MOLINA, B. Biologia y conservación del palmar de butiá (Butia capitata) en la Reserva de la biosfera bañados del este. Avances de investigación, Montevideo, n. 34, p.33, 2001.

MOREL, M.; SPERONI, G.; RIVAS, M. Morfología y fenologia de la floración de la palma Butia capitata (Mart.) Becc. In:SIMPÓSIO DE RECURSOS GENÉTICOS PARA AMÉRICA LATINA Y EL CARIBE, 5., 2005, Montevideo. Resúmenes... Montevideo: CNRF/INIA/FAGRO, 2005. p.184. 
NASCIMENTO, J. F.; FERREIRA, E. J. L.; CARVALHO, A L.; REGIANI, A. M. Parâmetros biométricos dos cachos, frutos e sementes da palmeira murmuru (Astrocaryum ulei Burret.) encontrada na região de Porto Acre, Acre. Revista Brasileira de Biociências, Porto Alegre, v.5, n.1, p.90-92, 2007. Suplemento

NUNES, A. M. Caracterização morfológica, físicoquímica e molecular de butiazeiros. 2007. 40f. Dissertação (Mestrado em Ciências) - Faculdade de Agronomia Eliseu Maciel, Universidade Federal de Pelotas, Pelotas, 2007.

PIEDADE, M. T. F.; PAROLIN, P.; JUNK, W. J. Estratégias de dispersão, produção de frutos e extrativismo da palmeira Astrocaryum jauari Mart. nos igapós do Rio Negro: implicações para a ictiofauna. Ecologia Aplicada, Lima, v.2, n.1, p.32-40, 2003.

REITZ, R.; KLEIN, R. M.; REIS, A. Projeto madeira do Rio Grande do Sul. Porto Alegre: SUDESUL, 1988. 525p.

RIO GRANDE DO SUL. Decreto n. ${ }^{0}$ 42.099, de 31 de dezembro de 2002. Declara as espécies da flora nativa ameaçadas de extinção no Estado do Rio Grande do Sul e dá outras providências. Disponível em: $<$ http:// www.fzb.rs.gov.br/downloads/index.htm>. Acesso em: 26 jul. 2008.

RIVAS, M.; BARILANI, A. Diversidad, potencial productivo y reproductivo de los palmares de Butia capitata (Mart.) Becc. de Uruguay. Agrociência, Montevideo, v.3. p.11-21, 2004.
ROGEZ, H. Açaí: preparo, composição e melhoramento da conservação. Belém: EDUFPA, 2000. 288 p.

ROSA, L.; CASTELLANI, T. T.; REIS, A. Biologia reprodutiva de Butia capitata (Martius) Beccari var. odorata (Palmae) na restinga do município de Laguna-SC. Revista Brasileira de Botânica, São Paulo, v.21, n.3, p.16, 1998.

ROSSATO, M. Recursos genéticos de palmeiras do gênero Butia do Rio Grande do Sul. 2007. 136 f. Tese (Doutorado em Ciências) - Faculdade de Agronomia Eliseu Maciel, Universidade Federal de Pelotas, Pelotas, 2007.

SCHMITZ, P. I.; NAUE, G.; BECKER, I. I. B. Os aterros dos Campos do Sul: a Tradição Vieira. In: Arqueologia pré-histórica do Rio Grande do Sul. Porto Alegre: Mercado aberto, 1991. p.221-250. (Série Documenta).

SCHLINDWEIN, G.; TONIETTO, S. M.; TONIETTO, A.; AZAMBUJA, A. C. de; FAVRETO, R.; PERINI, C. B. Caracterização física e química dos frutos de butiazeiro em Arambaré, RS. In: SIMPÓSIO NACIONAL DO MORANGO, 3., ENCONTRO SOBRE PEQUENAS FRUTAS E FRUTAS NATIVAS DO MERCOSUL, 2., 2006, Pelotas. Anais... Pelotas: Embrapa, 2006. p.282-285.

ZONTA, E. P.; MACHADO, A. A. Sanest - Sistema de análise estatística para microcomputadores. Pelotas: UFPel, 1995. 48 p. (SEI 066060, Categoria A) 